\title{
イソニアジド及びアシルイソニアジド誘導体の高速液体 クロマトグラフィーによる最適分析条件の検討
}

\author{
濱口聖美 ${ }^{\circledR *}$ ，花井俊彦 ${ }^{* *}$ ，久保博昭, 木下俊夫 ${ }^{* * *}$
}

(1989 年 7 月 20 日受理)

\begin{abstract}
イソニアジド及びアシルイソニアド誘導体（アセチルイソニアジド，プロピオニルイソニアジド， イ ソブチリルイソニアジド，ブチリルイソニアジド，ベンゾイルイソニアジド) の逆相イオン対 LCに よる最適分離条件を検討した。イソニアジド，アセチルイソニアジド及びプロピオニルイソニアジドの 分離には, 対イオン試薬としての脂肪族スルホン酸のうちドデカンスルホン酸が最適であった。イソニ アジド及びアシルイソニアジド誘導体は, 脂肪族スルホン酸とイオン対を形成することにより, 固定相 のオクタデシル基に保持されると考えられるが，アシルイソニアジド誘導体のアシル基も保持に影響を 与えていることが分かった。 イソニアジド及びアシルイソニアジド誘導体の保持比及び分配係数を求め て, Rekker による疎水性基定数と比較すると良好な直線関係を示した.
\end{abstract}

\section{1 緒言}

抗結核薬であるイソニアジド（INH）は肝臟で代謝 され，アセチルイソニアジド (AINH) として尿中に排 泄されることから，これらを定量することにより肝臟に おけるア七チル化能を測定することができる，又，この アセチル化能を测定することにより INHによる副作用 の発現を防ぐことも可能となる。従来，このINH 及び AINH の定量法には, 比色分析法 ${ }^{1)}$, 蛍光光度法 ${ }^{21}$, $\mathrm{GC}^{3)}$ な゙の外, HPLCによる方法が報告されている.

特に HPLCによる方法には, ジオクチルスルホコハク 酸4), オクチルスルホン酸 ${ }^{5)}$, ヘプタンスルホン酸6), ド デシル硫酸》なよ゙の対イオン試薬を使用した分析法が報 告されている.しかし，これらの分析法は系統的に対イ オン試薬を検討しておらず，又，生体液中の INH 及び AINH の分析では，いず机の場合も混在物との分離が 良好ではなく再現性も悪い。そこで, 各種脂肪族スルホ ン酸の対イオン試薬を用いて HPLCによるINH 及び AINH の分離分析法を検討し, 更に, 各種アシルイソ ニアジド誘導体の分配係数を求め, 分配係数と HPLC の保持時間を比較すると，アシルイソニアジド誘導体の

*ガスクロ業(株)：160 東京都新宿区西新宿 6-12-18

** (財)体質研究会国際解析研究所 : 606 京都府京都市 左京区百万遍パスツール研究所

*** 北里大学薬学部：108 東京都港区白金 5-9-1
構造を Rekker の疎水性基定数帛から推定できることが 分かったので報告する.

$$
2 \text { 実験 }
$$

\section{$2 \cdot 1$ 試 薬}

INH は和光純薬工業製を用い, アシルイソニアジド 誘導体である AINH, プロピオニルイソニアジド (PINH)，イソブチリルイソニアジド (iso-BINH)，ブ チリルイソニアジド (BINH), ベンゾイルイソニアジ ド (BzINH) は, 酸無水物又は酸クロリドを用い, 常 法により INH から合成し, 元素分析及び質量分析法に より同定した．各々 $500 \mu \mathrm{g} / \mathrm{ml}$ 水溶液に調製し適宜精 製水で希釈して使用した. 対イオン試薬のうち炭素数 1 11 までの脂肪族スルホン酸ナトリウムは東京化成工 業製，炭素数 12 のスルホン酸ナトリウム及び硫酸ナト リウムは，ガスクロ工業製を用いた。アヤトニトリルは LC 用，1ーオクタノールは特級を，共に和光純薬工業製 を用いた。

\section{$2 \cdot 2$ 装 置}

HPLC 装置として, ポンプは Model 576, 検出器に は Model 502U 紫外可視分光検出器, 各々ガスクロ工 業製を、インジェクターは Model 7125 レオダイン製を 使用した。記録計は Chromato-integrator D-2000 日立 製を用い，遠心分離器はクラボウ DISKBOY FB-4000 を, 分光光度計は Hitachi Model 200-20 型を使用し 
た。

\section{$2 \cdot 3$ 操 作}

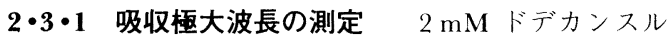
ホン酸ナトリウムを含む $24 \%$ ア セトニトリル水溶液 ( $\mathrm{pH} 3$ にリン酸で調節) と INH， AINH 及び PINH の $10 \mu \mathrm{g} / \mathrm{ml}$ 水溶液を等量混合した溶液のスペクトルを紫 外分光光度計により測定したところ，265 nm に吸収極 大波長を示したので, 以後クロマトグラフィ一の検出に はこの波長を使用した。

\section{2・3・2 INH 及びアシルイソニアジド誘導体の分配} 係数の測定 INH及びアシルイソニアジド誘導体 (AINH, PINH, iso-BINH, BINH, BzINH) 条々をリン 酸で $\mathrm{pH} 3$ に調節した水溶液に溶解し， $1 \mathrm{mg} / 10 \mathrm{ml} の$ 濃度の試料溶液とした。試験管に各試料溶液 $10 \mathrm{ml}$ と 等量の1-オクタノールを添加し激しくかき混ぜた後, 遠心分離し水相及び 1 -オク夕ノ一ル相の吸光度を波長 $265 \mathrm{~nm}$ で測定した.

\section{$2 \cdot 3 \cdot 3$ 移動相中のイオン対試料 $10 \mathrm{mM}$ のリン} 酸一ナトリウムを含む 10,15 及び $20 \%$ のアセトニトリ ル水溶液を，リン酸で $\mathrm{pH} 3$ に調節し，この浴液に 2 -5 mM の各種対イオン試薬を添加したものを移動相 として, INH, AINH 及び PINH の分離条件を検討し た.

2・3・4 HPLC 条件 分析カラムとしては粒径 5 $\mu \mathrm{m}$ の Inertsil ODS-2 を坟さ $150 \mathrm{~mm}$, 内径 $4.6 \mathrm{~mm}$ の
ステンレス管に充てんしたもの（ガスクロ工業製）, ガードカラムは Inertsil ODS-2 を長さ $10 \mathrm{~mm}$, 内径 $4.0 \mathrm{~mm}$ のステンレス管に充てんしたものを使用した. カラム温度は室温とし, INH, AINH 及び PINH の分 離には, 移動相として $2 \mathrm{mM}$ ドデカンスルホン酸ナト リウム及び $10 \mathrm{mM}$ リン酸一ナトリウムを含む $22.5 \%$ アセトニトリル水溶液を, リン酸で $\mathrm{pH} 3$ に調節したも のを使用した。流量は $1.0 \mathrm{ml} / \mathrm{min}$ とし，検出波長 265 $\mathrm{nm}(0.032$ AUFS $)$ で測定し, 試料は $10 \mu \mathrm{l}$ 注人した。

又, INH, AINH, PINH, iso-BINH 及び BzINH の分離 には，BzINHの溶出を速めるため，アセトニトリルの 濃度を $24 \%$ にして前述の条件で分析を行った。

\section{3 結果及び考察}

\section{3・1 内標準物質の理論的な選択法}

Rekker が示す疎水性基定数1により，INH 及びアシ ルイソニアジド誘導体中の各々の基について疎水性基定 数の合計值 $\left(\log p^{*}\right)$ を求め, Table 1 に示した. これ を理論值 $\log p$ とする. 又, 実験より求めた INH とア シルイソニアジド誘導体の1-オクタノール/水における 分配係数を実測値 $\log P$ として, 画者の相関係数を求め たところ 0.984 であり理論值 $\log P^{*}$ の信頼性は高いも のと考えられる. 次に, 溶離液として $\mathrm{pH} 3$ のリン酸水 溶液を用いて, 検出波長 $265 \mathrm{~nm}$, 流量 $1.0 \mathrm{ml} / \mathrm{min}$ で, $\mathrm{INH}$ と $\mathrm{AINH}$ の保持比 $\left(K^{\prime}\right)$ を求めた。この $K^{\prime}$ の対 数值 $\log K^{\prime}$ を $X$ 軸, 理論值 $\log P$ 及び実測值 $\log P^{\prime}$ を

Table 1 Calculated $\log P$ values derived from fragment

\begin{tabular}{|c|c|c|c|c|c|c|}
\hline Chemicals & INH & AINH & PINH & iso-BINH & BINH & $\mathrm{BzNH}$ \\
\hline \multicolumn{7}{|l|}{ Fragment } \\
\hline & $\mathrm{CONH}$ & $\mathrm{CONH}$ & CONH & $\mathrm{CONH}$ & $\mathrm{CONH}$ & $\mathrm{CONH}$ \\
\hline $\log P^{*}$ & -0.409 & -0.409 & -0.409 & -0.409 & -0.409 & -0.409 \\
\hline Fragment & $\mathrm{NH}_{2}$ & NHCO & NHCO & NHCO & NHCO & NHCO \\
\hline $\log P^{*}$ & -1.428 & -1.795 & -1.795 & -1.795 & -1.795 & $-0.934(\mathrm{ar})$ \\
\hline Fragment & - & $\mathrm{CH}_{3}$ & $\mathrm{CH}_{2} \mathrm{CH}_{3}$ & $\mathrm{CH}\left(\mathrm{CH}_{3}\right)_{2}$ & $\left(\mathrm{CH}_{2}\right)_{2} \mathrm{CH}_{3}$ & $\mathrm{Bz}$ \\
\hline $\log P^{*}$ & - & 0.702 & 1.232 & 1.639 & 1.762 & 1.886 \\
\hline $\log P$ & -1.837 & -1.502 & -0.972 & -0.565 & -0.442 & 0.543 \\
\hline $\log P^{\prime}$ & -2.052 & -1.445 & -0.817 & -0.425 & -0.318 & 0.317 \\
\hline
\end{tabular}

* Rekker's hydrophobic fragmental constant ${ }^{1)} . \log P$ : calculated $\log P^{*}$ values of each chemical; $\log P^{\prime}$ : partition coefficient measured in 1-octanol/water. Abbreviations : INH, isoniazid; AINH, acetylisoniazid; PINH, propionylisoniazid ; iso-BINH, iso-butyrylisoniazid ; BINH, butyrylisoniazid ; BzINH, benzoylisoniazid 
各々 $Y$ 軸としたグラフを Fig. 1 に示す. $\log K^{\prime}$ と $\log P$ 及び $\log P^{\prime}$ の相関係数は各々 $0.997,0.996$ 亡良好な直線 関係を示した。

\section{$3 \cdot 2$ 対イオン試薬の検討}

移動相中の対イオン試薬と INH, AINH 及び PINH の各保持時間との関係を Fig. 2 に示す。一般にスルホ ン酸基を有する対イオン試薬は，塩基性の試料物質とイ オン対を形成し，保持は対イオン試薬の脂肪鎖と固定相 であるオクタデシル基との分子間相互作用により行われ ると考えられている. pH 3 の水溶液中では, ピリジン 環の窒素及びヒドラジンのアミノ基はプロトン付加して

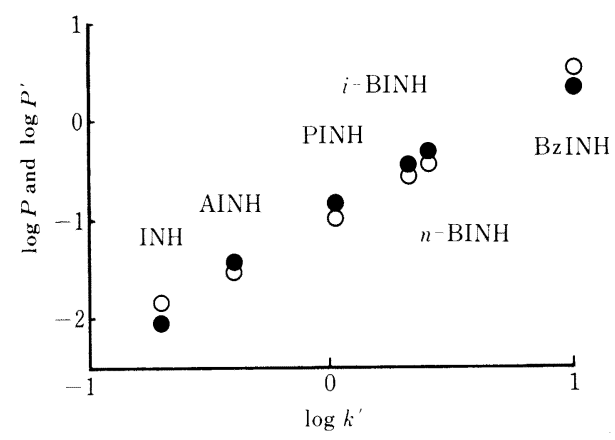

Fig. 1 Relationship between partition coefficients and capacity ratios

$\log P\left(-O^{-}\right.$; calculated by Rekker's hydrophobic fragmental constants) and $\log P^{\prime}\left(-\mathbf{O}^{-}\right.$; measured by 1 -octanol/water partition) values are given in Table 1. Abbreviation (INH, AINH, PINH, iso-BINH, BINH, BzINH) : see Table 1 .
いると考えられる. INH はピリジニウムとヒドラジニ ウムイオンの 2 か所でイオン対形成が考えられ，アシ ルイソニアジドはピリジニウムイオンのみがイオン対を 形成していると考えられる (Fig. 3). Fig. 2 に示すよ うに，対イオン試薬として使用した脂肪族スルホン酸の 炭素鎖が垓くなるほど, INH, AINH 及びPINHのイ オン対の保持は長くなった。 INH の保持時間は炭素数 4 までは AINH や PINH より短く, 炭素数 5 7では AINH とPINH の間にあり, 炭素数 8 以上では AINH やPINHより長くなったＩNH の溶出挙動を調べるた

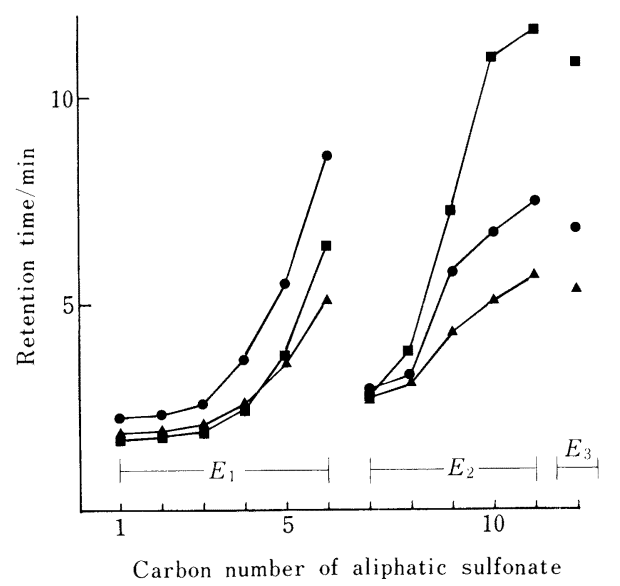

Fig. 2 Relationship between ion-pair reagent and retention time

Eluent $E_{1} ; 10 \%$ acetonitrile solution $(\mathrm{pH} 3)$; $E_{2} ; 15 \%$ acetonitrile solution $(\mathrm{pH} 3) ; E_{3} ; 20 \%$ acetonitrile solution ( $\mathrm{pH} 3) . \mathbf{\square}: \mathrm{INH}$; $\mathrm{AINH} ; \mathrm{O}: \mathrm{PINH}$
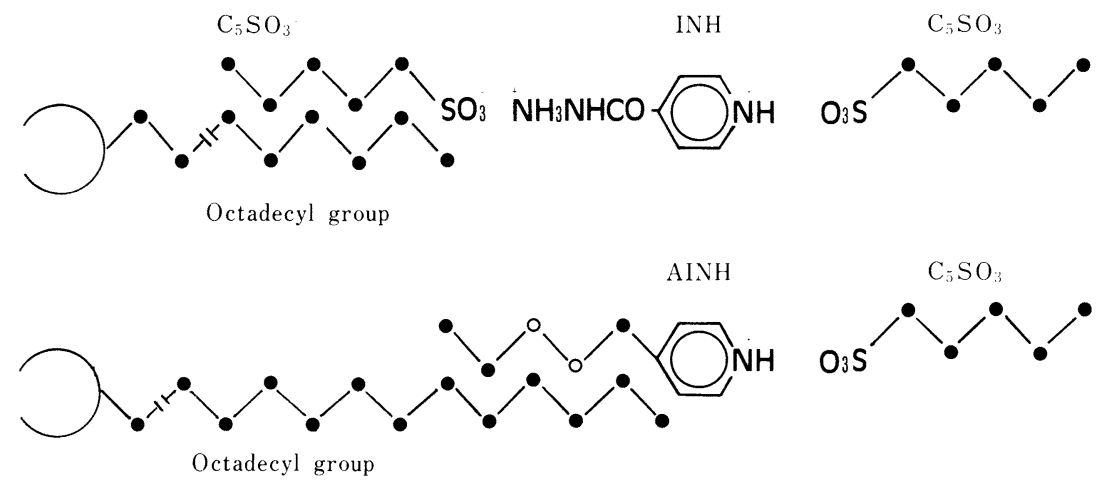

Fig. 3 Model of interaction between octadecyl group and isoniazid (INH) or acetylisoniazid (AINH)

: carbon atom; $\bigcirc$ : nitrogen atom; $\mathrm{C}_{5} \mathrm{SO}_{3}$ : pentanesulfonate ion 
めに, Fig. 2 の同じ溶離液で求めた対イオンの炭素数 6 までの $\log K^{\prime}$ と炭素数の関係を求めた。この結果, INH は炭素数 5 で AINH より遅く溶出しており，この $\log K^{\prime}$ 亡炭素数の関係を延長すると, 炭素数 8 のとこ ろでINH はPINH より遅く溶出されることが推察さ れた。この予測は異なる溶離液で求めた結果, つまり, Fig. 2 の炭素数 7 以上での溶出順序を説明できた。 ミノ基の対イオンとのイオン対形成による保持時間の増 加は, $\log K^{\prime}$ 值で 1.3 倍であった.この結果と Fig. 1 の結果を考慮すると，対イオンの鎖長を変えたときの INH の溶出順序を予測することができ，必要な内標準 物質の選択も可能亡思われる. 又, 炭素数 1 12まで の脂肪族スルホン酸を用いて, INH, AINH の分離条件 を検討したところ，炭素数が多いほど INH, AINHの 分離が良かった。そこで, 炭素数 12 のドデカンスルホ ン酸ナトリウムとドデシル硫酸ナトリウム (SDS) を用 いて，これらの $1.0 \sim 2.5 \mathrm{mM}$ の濃度範囲における $\mathrm{INH}$ と AINH の分離度及び分離係数を測定した。Fig. 4 に 示すように, SDS の濃度が $2.0 \mathrm{mM}$ 以上になると分離 度, 分離係数も急激に大きくなり, わずかな濃度変化に より保持時間の再現性が低下した。 又, SDS は界面活 性効果による泡立ちのため調製しにくいことから，適切 な対イオン試薬として $2.0 \mathrm{mM}$ のドデカンスルホン酸 ナトリウムを用いた. Fig. $5(\mathrm{a}, \mathrm{b})$ に INH, AINH, PINH, iso-BINH 及びBzINH の最適分離条件下におけ る HPLCのクロマトグラムを示す. BINHはisoBINH とピークが重なってしまうため示さなかった。 Fig. 5(a) 及び Fig. 1 より INH と AINH 分離定量に

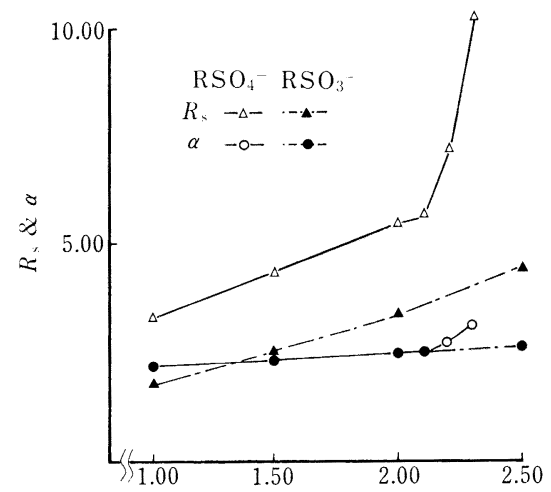

Concentration of ion pair reagent $\mathrm{mM}$

Fig. 4 Resolution $\left(R_{\mathrm{S}}\right)$ and separation factor $(\alpha)$ of isoniazid and acetylisoniazid for dodecanesulfonate $\left(\mathrm{RSO}_{3}{ }^{-}\right)$and dodecylsulfate $\left(\mathrm{RSO}_{4}{ }^{-}\right)$

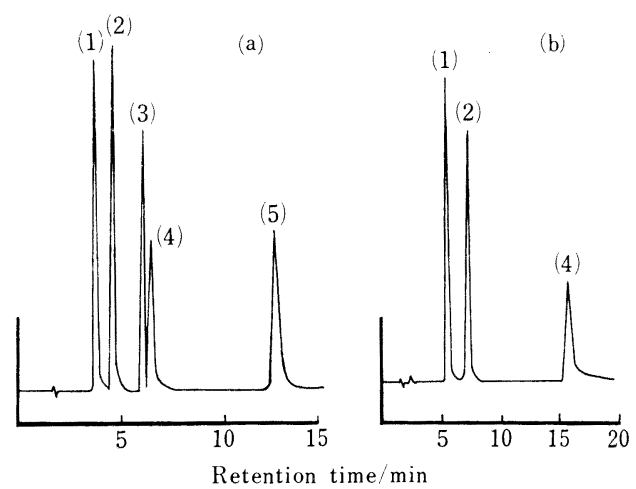

Fig. 5 Chromatograms of a mixture of $\operatorname{AINH}(1)$, PINH (2), iso-BINH (3), INH (4) and BzINH (5)

Abbreviation: see Table 1. (a) : column, 150 $\mathrm{mm} \times 4.6 \mathrm{~mm}$ i.d. packed Inertsill ODS-2 (5 $\mu \mathrm{m})$; eluent, $24 \%$ acetonitrile solution containing $2.0 \mathrm{mM}$ dodecanesulfonate $(\mathrm{pH} 3)$; flow rate, $1.0 \mathrm{ml} / \mathrm{min}$; column temp., ambient. (b) : chromatographic condition is the same as in Fig. 5 (a) except for acetonitrile concentration $(22.5 \% \sim 24 \%)$.

おける内標準物質として，INH のピークとも重ならな いPINH が，保持時間からも適当であった $\{$ Fig. 5 (b) $\}$.

$\left(\begin{array}{l}1988 \text { 年 } 10 \text { 月, 日本分析化学会 } \\ \text { 第 } 37 \text { 年会において一部発表 }\end{array}\right)$

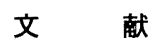

1) H. G. Boxenbaum, S. Rigelman : J. Pham. Sci., 63, 1191 (1974)

2) W. A. Olson, P. G. Dayton, Z. H. Israili, A. W. Pruiff: Clin. Chem., 23, 745 (1977).

3) J. A. Timbrell, J. M. Wright, C. M. Smith : J. Chromatogr., 138, 165 (1977).

4) S. J. Saxena, J. T. Stewart, I. L. Honigberg, J. G. Washington, G. R. Keene: J. Pharm. Sci., 66, 813 (1977).

5) M. R. Holdiness : J. Liq. Chromatogr., 5, 707 (1982).

6) J.-O. Svenson, A. Muchtar. O. Ericsson : J. Chromatogr., 341, 193 (1985).

7) M. Guillaumont, M. Leclercq, Y. Frobert, B. Guise: J. Chromatogr., 232, 369 (1982).

8) R. F. Rekker: "The Hydrophobic Fragmental Constant”, (1977), Elsevier (Amsterdam).

is

Optimization of HPLC analysis of isoniazide and acylisoniazide derivatives.

Kiyomi Hamaguch * 
Toshihiko HanaI ${ }^{* *}$, Hiroaki Kubo and Toshio Kinoshita ${ }^{* * *}$, ( ${ }^{*}$ Gasukuro Kogyo Inc., 6-12-18, Nishishinjuku, Shinjuku-ku, Tokyo 160; ${ }^{* *}$ International Institute of Technological Analysis, Health Research Foundation, Institute Pasteur de Kyoto, Hyakumanben, Sakyoku, Kyoto-shi, Kyoto 606; ${ }^{* * *}$ School of Pharmaceutical Sciences, Kitasato University, 5-9-1, Shirokane, Minato-ku, Tokyo 108)

Optimal conditions of separation for isoniazid and acylisoniazid derivatives (acetylisoniazid, propionylisoniazid, isobutyrylisoniazid, butyrylisoniazid, benzoylisoniazid) were determined in reversed-phase ion-pair LC. Sodium dodecanesulfonate was the best ion-pair reagent among alkylsulfonates. When the carbon number of alkylsulfonate was below 4, the elution order was isoniazid, acetylisoniazid and propionylisoniazid. When the carbon number of alkylsulfonate was 5 , the elution order of isoniazid and acetylisoniazid was changed. Further when its number was 8 , the elution order of isoniazid and propionylisoniazid was reversed. The acyl group of acylisoniazid also affected their retention. The conditions of HPLC were as follows: Column, Inertsil ODS-2 ( $5 \mu \mathrm{m}, 150 \times 4.6 \mathrm{~mm}$ i.d.) ; eluent, $24 \%$ aqueous acetonitrile solution containing $2.0 \mathrm{mM}$ sodium dode- canesulfonate $(\mathrm{pH} \mathrm{3})$; flow rate, $1.0 \mathrm{ml} / \mathrm{min}$; column temperature, ambient. Retention time was $6.30 \mathrm{~min}$ for isoniazid, $3.69 \mathrm{~min}$ for acetylisoniazid, $4.49 \mathrm{~min}$ for propionylisoniazid, $6.06 \mathrm{~min}$ for isobutyrylisoniazid, $6.25 \mathrm{~min}$ for butyrylisoniazid and $12.58 \mathrm{~min}$ for benzoylisoniazid. The capacity ratios $\left(\log k^{\prime}\right)$ of isoniazid and acylisoniazid derivatives and the partition coefficients measured in 1octanol/water $\left(\log P^{\prime}\right)$ were in good linear relation with those calculated by Rekker's hydrophobic fragmental constants $(\log P)$. Coefficient of correlation for firstorder regression lines of $\log P-\log P^{\prime}, \log k^{\prime}-\log P$ and $\log k^{\prime}-\log P^{\prime}$ plots were $0.984,0.997$ and $0.996 \quad(n=6)$, respectively. This calculation method could generally be used to find an appropriate internal standard compound for reversed-phase LC.

(Received July 20, 1989)

\section{Keyword phrases}

analysis of isoniazid and acylisoniazid derivatives, alkylsulfonate as ion-pair reagent, reversed-phase ion-pair LC, relation between $\log k^{\prime}$ and $\log P$. 